\title{
IDENTIFICATION AND QUANTIFICATION OF PHENOLIC COMPOUNDS IN WHITE WINES FROM THE APOLD VINEYARD
}

\author{
Ecaterina, LENGYEL ${ }^{1}$ and Letitia OPREAN ${ }^{2}$ \\ „„Lucian Blaga” University of Sibiu, Sibiu, Romania, ecaterina.lengyel@ulbsibiu.ro \\ ${ }_{2}^{2}$, Lucian Blaga” University of Sibiu, Sibiu, Romania, letitia.oprean@ulbsibiu.ro
}

\begin{abstract}
Wines contain a wide range of aromatic compounds, each having its share in the characterization of the end product. This paper aims at highlighting the phenolic compounds that are present in three types of wine from the Apold Vineyard, compounds that have been determined by modern chromatographic methods. Anthocyanins, flavans, flavones and flavonoids, phenolic acids and microphenolic compounds have been determined in three wines: Pinot gris, Neuburger and Furmint. The results have led to the characterization of these wines and their classification according to the parameters acknowledged by the international authorities.
\end{abstract}

KEYWORDS: phenolic compounds, Pinot gris, Neuburger, Furmint, HPLC

\section{INTRODUCTION}

Phenolic compounds have an important role in the formation of wine flavours, as they play an active part in improving the consumers' health (Cotea et al., 2009; Cotea et al., 2006). The most common compounds found in grapes are the hydroxybenzoic and hydroxycinnamic phenolic acids, which, by esterification with the alcohols present in wine, form specific aromatic compounds, such as methyl and ethyl vanillates, and ethyl cinnamate (Methyl trans-3-phenylpropenoic acid) (Jakson 2008; Perez-Magarino et al., 2004; Tița et al. 2013; Târdea, 2007). A predecessor of the ethyl cymate is the ferulic acid, which lends fruitiness to the wine alongside thiol compounds, such as mercapto-pentanone, which reacts with the oxidized phenolic compounds (thiones) (Lengyel, 2012; Du Toit et al, 2006; Fernandez et al., 2007). The aromatic make-up of wines is closely related to the region from which the grapes come, but also depends on soil structure and edaphic and climatic factors (Hernandez et al., 2009; Francis et al., 2005; King et al., 2011). This study attempts an evaluation of phenolic compounds in wines from the Apold Vineyard, a wine-producing region located at the heart of Transylvania, well-known for its particularly aromatic and slightly astringent wines.

\section{Materials and methods}

Wines from the Pinot gris, Neuburger and Furmint varieties, white varieties from the 2013 vintage of the Apold Vineyard.

The method for the identification and quantification of the phenolic compounds consisted in injecting directly into the chromatographic column the Agilent 1200 HPLC chromatograph equipped with an autosampler and UV-VIS detector set at $220 \mathrm{~nm}$.

The phenolic compounds were identified by comparing the retention times with those of the standard.
The individual quantification of phenols was performed using the calibration curves obtained for each standard.

\section{Results and discussion}

As it may be seen in Figure 1, the values of anthocyanins determined in the three varieties of wine ranged between $205.991 \mathrm{mg} / \mathrm{L}$ for Furmint and a maximum of $209.129 \mathrm{mg} / \mathrm{L}$ for Neuburger. The determined values are specific to white wines, red wines being known to lead to an accumulation of 500-800mg anthocyanins/L.

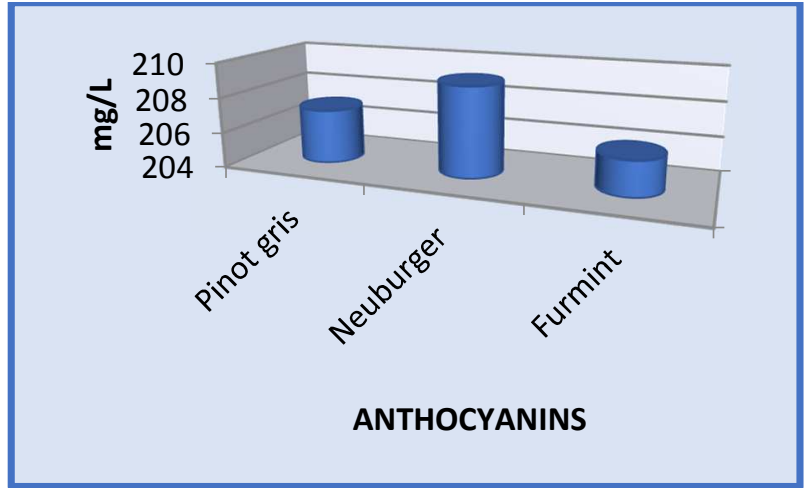

Figure 1. Accumulation of anthocyanins in Pinot gris, Neuburger and Furmint, wines originating from the Apold Vineyard, vintage of 2013

Flavans, compounds which are the source of the pigmentation of the grapes and implicitly of wine, derive from flavan (2-phenylbenzopyran, chroman), having a benzopyran ring included in its molecule structure. In grapevines, they are found both as monomers (in seeds and grape peel) and dimers (in grape pulp) and as oligomers. These polymerize forming catechins, which are included in the make-up of catechin tannins. Figure 2 shows that the most significant values of flavans are present in the Furmint variety, i.e. $0.237 \mathrm{mg} / \mathrm{L}$, the lowest values being found in the Pinot gris wines, only $0.188 \mathrm{mg} / \mathrm{L}$. 


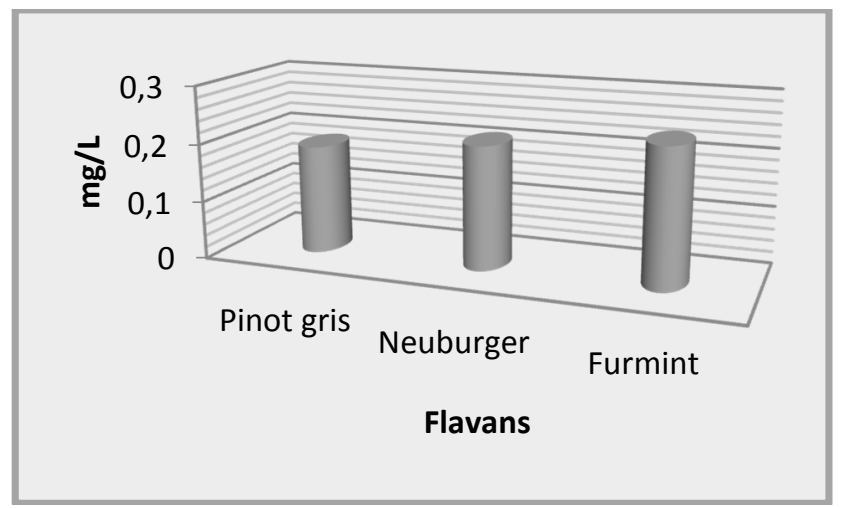

Figure 2. Accumulation of flavans in Pinot gris, Neuburger and Furmint, wines originating from the Apold Vineyard, vintage of 2013

The high content of flavones and flavonols is illustrated in Figure 3 also in the case of Furmint, with a value of $0.413 \mathrm{mg} / \mathrm{L}$, followed by Neuburger, with $0.408 \mathrm{mg} / \mathrm{L}$, and Pinot gris, with $0.388 \mathrm{mg} / \mathrm{L}$.

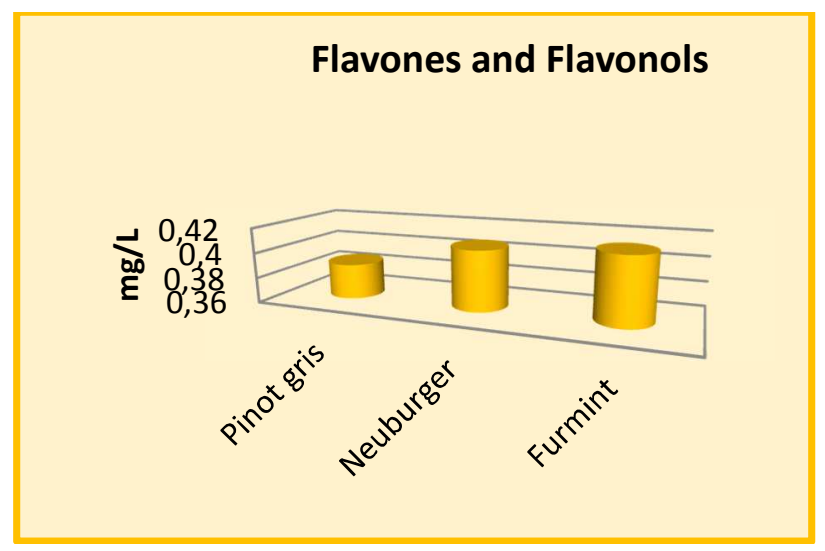

Figure 3. Accumulation of flavones and flavonols in Pinot gris, Neuburger and Furmint, wines originating from the Apold Vineyard, vintage of 2013

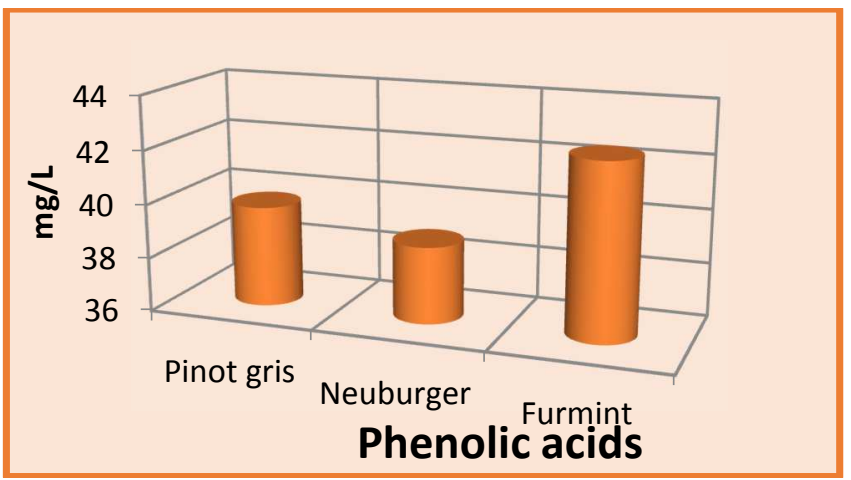

Figure 4. Accumulation of phenolic acids in Pinot gris, Neuburger and Furmint, wines originating from the Apold Vineyard, vintage of 2013

Phenolic acids lead to a sour, astringent taste and precipitate the metals in the must and wine. Figure 4 indicates a greater accumulation of phenolic acids in Furmint, i.e. $42.461 \mathrm{mg} / \mathrm{L}$, compared with Neuburger which has $38.851 \mathrm{mg}$ phenolic acids/L. Pinot gris presented a value of $39.735 \mathrm{mg}$ phenolic acids/L.

Microphenolic compounds showed variations between 23.996mg/L for Neuburger and $32.119 \mathrm{mg} / \mathrm{L}$ for Pinot gris. In Furmint, a value of $28.456 \mathrm{mg}$ microphenolic compounds/L was identified. These values contribute to the sensory characterization of the wines.

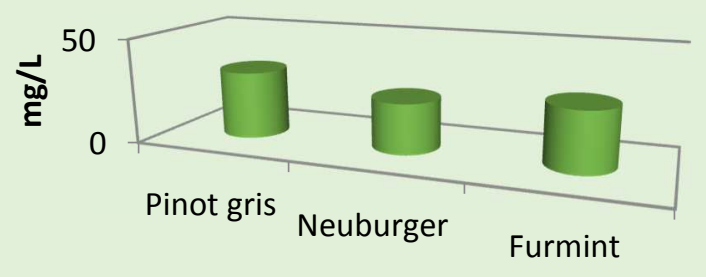

Microphenolic compounds

Figure 5. Accumulation of microphenolic compounds in Pinot gris, Neuburger and Furmint, wines originating from the Apold Vineyard, vintage of 2013

The values of the phenolic compounds obtained for the three wines under examination led to their sensory characterization, as follows:

Pinot gris is a balanced wine with a delicate aroma, a bittersweet and slightly spicy taste. It features flavour, richness in ingredients and extra activity, and its special finesse.

Neuburger is a wine with a greenish yellow colour with golden hues. It has fine flavours of citrus, and it is full-bodied and complex. After it matures, it becomes soft and extremely pleasant.

Furmint is a straw yellow to yellow-greenish wine, with high acidity, light citrus aromas, lively and refreshing.

\section{CONCLUSIONS}

The anthocyanins accumulated in the three varieties of wine give them their freshness and colour.

The flavans, compounds which lead to the pigmentation of the grapes, contribute to the refinement of the wine, endowing it with its specific sensory attributes.

Flavones and flavonols, quantified by chromatographic methods, have values that grant the studied wines positive qualities, suave nuances and finesse.

Phenolic acids are found in a balanced amount, leading to a slightly sour taste.

Microphenolic compounds lead to the stabilization of the sensory qualities of wines, lending slightly astringent nuances, specific flavours and colour.

\section{ACKNOWLEDGMENT}

This work was supported by the strategic grant POSDRU/159/1.5/S/133255, Project ID 133255 (2014), cofinanced by the European Social Fund within the Sectorial Operational Program Human Resources Development 20072013

\section{REFERENCES}

1. Cotea, D.V., Zănoagă, C.V., Cotea V.V., 2009, Tratat de oenochimie, vol.I, Ed. Academiei Române Bucureşti

2. Cotea, V.V., Cotea, D. V., 2006, Tehnologii de producere a vinurilor, Ed. Academiei Române, București

3. Lengyel, E, 2012, primary aromatic character of wines, Acta Universitatis Cibiniensis, Series E: Food Technology, 16(1), 3-18

4. Jackson, R., Wine science, Principles and applications, ed. Springer, 2008

5. Pérez-Magariño S., González-San José, M.L., 2004, Evolution of flavanols, anthocyanins, and their derivatives 
during the aging of red wines, elaborated from grapes harvested at different stages of ripening J.Agric. Food Chem., 52, 1181-1189

6. King, E.S., Osidacz, P., Curtin, C., Bastian, S.E.P., Francis, I.L., 2011, Assessing desirable levels of sensory properties in Sauvignon Blanc wines- consumer preferences and contribution of key aroma compounds, Australian Journal of Grape and Wine Research, 17, (2), 169-180

7. Târdea, C., 2007, Chimia și analiza vinului, Ed. Ion Ionescu de la Brad

8. Tița, O., Oprean, L., Lengyel, E., Iancu, R., Păcală, M., Mutu, D., Gabor, D., Tița, M., 2013, Comparative studies regarding the accumulation of phenolic compounds in musts from Recas vineyard, from aromatic varieties, semi aromatic and red varieties, SGEM Conference, 2013, Albena, 121-128

9. Du Toit, W., Lisjak, K., Marais, J., Du Toit, M., 2006, The effect of micro-oxygenation on the phenolic composition, quality, and aerobic wine-spoilage microorganisms of different South Africa red wines, South African Journal of Enology and Viticulture, 27, 57-67

10. Fernandez, K., Kennedy, J.A., Agosin, E., 2007, Characterization of Vitis Vinifera L. Cv. Carmanere grape and wine proanthocyanidins. Journal of Agric. Food Chemistry, 55, 3675-3680

11. Francis, I.L., Newton, J.L., 2005, Determining wine aroma from compositional data, Australian Journal of Grape and Wine Research, 11, (2), 114-126

12. Hernandez, D., Gallo, V., Recamales, A.F., MelendezMarinez, A.J., Gonzalez-Miret, M.L., Heredia, F.J., 2009, Effect of storage on the phenolic content, volatile composition and colour of white wines from the varieties Zalema and Colombard, Food Chemistry, 113, 530-537 